\title{
Misturas, artesanias e autonomia: Ensino e aprendizagem em ciências da natureza em um espaço não formal
}

\section{Mixtures, handicraft and autonomy: teaching and learning in sciences of nature in a non-formal space}

\author{
Daniela Alves da Silva (contatodanialves@gmail.com) \\ Universidade Federal do Rio Grande do Sul (UFRGS) \\ José Vicente Lima Robaina (joserobaina1326@gmail.com) \\ Universidade Federal do Rio Grande do Sul (UFRGS) \\ Aline Guterres Ferreira (alinegufe@gmail.com) \\ Universidade Federal do Rio Grande do Sul (UFRGS) \\ Greice de Souza (greicesh32@gmail.com) \\ Universidade Federal do Rio Grande do Sul (UFRGS)
}

Resumo: O presente trabalho apresenta os resultados de uma pesquisa desenvolvida no Centro de Referência de Assistência Social - CRAS localizado no município de Eldorado do Sul/RS. A pesquisa buscou investigar aspectos relevantes no ensino e aprendizagem em Ciências da Natureza (Química, Física e Biologia) e saberes da experiência das participantes através da aplicação de uma abordagem temática inspirada em Paulo Freire (1987) em um espaço não formal de ensino. Utilizou-se como instrumento de pesquisa a observação - participante e questionário. A experiência desenvolvida oportunizou a presente reflexão, autocrítica e futuros desafios, tal como pensar como os espaços não formais, como a própria escola pode contribuir como ferramenta de construção de novos paradigmas onde o educando seja o principal motivador-construtor de seus -Conhecimentos acerça da Ciências da Natureża:

Palavras-chave: Ciências da Natureza; espaços não formais; ensino e aprendizagem.

Abstract: The present work presents the results of a research developed at the Social Assistance Reference Center - CRAS located in the city of Eldorado do Sul/RS. The research sought to investigate relevant aspects of teaching and learning in Natural Sciences (Chemistry, Physics and Biology) and knowledge of the participants' experience inspired by Paulo Freire (1987) in a non-formal teaching space. Observation - participant and questionnaire - was used as a research instrument. The experience developed enabled the present reflection, self-criticism and future challenges, such as thinking how nonformal spaces, how the school itself can contribute as a tool for building new paradigms where the student is the main motivator-builders of his knowledge about Science from nature.

Keywords: Natural Sciences; non-formal spaces; teaching and learning.

Recebido em: 30 /04/ 2020

Aceito em: $19 / 11 / 2020$ 


\section{INTRODUÇÃ̃}

Buscou - se através de uma abordagem temática intitulada "misturas, artesanias e autonomia: organizando saberes construídos a partir do cotidiano através da ciências da natureza" mobilizar saberes da experiência das participantes associando com saberes escolares de Ciências da Natureza (Química, Física e Biologia).

A proposta de abordagem foi inspirada na perspectiva de educação libertadora e humanista de Paulo Freire $(1997 ; 2009 ; 2013$; 2014) onde a mesma é desenvolvida em um processo de diálogo e problematização a partir do contexto de realidade das participantes. Ainda propõem conteúdos problemáticos construídos coletivamente pelo educador-educando e educando-educador em um exercício de comunicação e diálogo (FREIRE, 2013).

A abordagem temática proposta por Freire $(1997 ; 2009 ; 2013 ; 2014)$ destaca-se ao apresentar elementos importantes que contrapõe um ensino tradicional e bancário na Educação em Ciências da Natureza, além da sua experiência partir da alfabetização de jovens e adultos em espaços não formais de educação. Demétrio Delizoicov (2008) considera que um ensino em Ciências na perspectiva Freiriana deva ser levado em consideração as questões do educando e que "es necesaria la elección y definición de objetos de conocimiento en torno de los cuales girará el diálogo entre el conocimiento científico del profesor y el conocimiento previo del alumno"(DELIZOICOV, 2008, p. 40).

Ampliando o ensino e aprendizagem em Ciências da Natureza para os espaços não formais, podemos potencializar a inovação de práticas pedagógicas que valorizem aspectos educativos voltados a uma educação comprometida com o diálogo e a problematização, garantindo com êxito aproximações, relações, atuações valorosas e transformadoras para a educação em Ciências da Natureza em sintonia com questões atuais e contemporâneas que se atravessam tanto no espaço formal e nos espaços não formais de educação.

Jacobucci (2008) comenta que a definição do que é um espaço não Formal de Educação é muito mais complexa do que imaginamos, a autora destaca a importância de se contextualizar o Espaço Formal de Educação como um "espaço escolar, que está relacionado às Instituições Escolares da Educação Básica e do Ensino Superior, definidas na Lei 9394/96 de Diretrizes e Bases da Educação Nacional” (JACOBUCCI, 2008, p. 56).

Já o espaço não formal a autora (JACOBUCCI, 2008) conceitualiza como espaços educativos fora do espaço escolar, sugerindo duas categorias: locais que são Instituições (Museus, Centros de Ciências, Parques Ecológicos, Parques Zoobotânicos, Jardins Botânicos, Planetários, Institutos de Pesquisa, Aquários, Zoológicos, dentre outros.) e 
locais que não são Instituições (teatro, parque, casa, rua, praça, terreno, cinema, praia, caverna, rio, lagoa, campo de futebol, dentre outros inúmeros espaços).

Os espaços não formais de ensino possuem papel fundamental na formação de todas e todos que participam, favorecendo a formação de novas sensibilidades e atitudes (ROCHA; FACHÍN-TERÁN, 2010) bem como a de estimular a integração destes espaços para um ensino e aprendizagem em Ciências da Natureza contextualizado e integrado as experiências dos participantes.

Considerando o referencial teórico, o objetivo da oficina temática foi de aprofundar o entendimento e a compreensão da prática docente através da abordagem temática em um espaço não formal como parte integrante do estágio interdisciplinar obrigatório do curso de Licenciatura em Educação do Campo - Ciências da Natureza da Universidade Federal do Rio Grande do Sul.

A experiência foi desenvolvida em dois momentos durante o período de 25 de setembro a 22 de novembro de 2018. O primeiro momento denominado como tempo de observação - participante (GIL, 2008), onde o mesmo permitiu o aprofundamento e o levantamento preliminar de informações sobre o espaço não formal e das participantes, $o$ segundo momento constituiu em encontros semanais às terças feiras e quintas feiras, pela parte da manhã e tarde, com mulheres entre 14 a 70 anos, nas dependências do Centro de Referência de Assistência Social - CRAS localizado no município de Eldorado do Sul/RS, onde possui a função exclusiva no trabalho social com famílias por meio do serviço de Proteção e Atendimento Integral às Famílias (PAIF).

Inaugurado em junho de 2015, o CRAS foi construído, equipado e capacitado com o objetivo de garantir a promoção da segurança de convívio familiar e comunitário, de renda, de acolhida, de autonomia e de sobrevivência junto às famílias em situação de vulnerabilidade social com vistas a fortalecer os vínculos familiares e comunitários.

O CRAS recebe semanalmente mulheres e crianças beneficiárias do programa de Serviço de Convivência e Fortalecimento de Vínculos (SCFV) através da Secretária Social e de Trabalho de Eldorado do Sul, é um órgão público, onde trabalham técnicos, profissionais na área da Educação, Saúde e Assistência Social, empresas terceirizadas, concursados e estagiários.

Recebe em média 15 crianças em dois turnos e 13 mulheres no turno da tarde. $\mathrm{O}$ grupo de mulheres é nomeado como Grupo Compartilhando Saberes. O grupo em um primeiro momento foi organizado de forma autônoma por mulheres atendidas pelo CRAS em meados de 2012. Mulheres, que em sua grande maioria eram idosas se reuniam para compartilhar diversos saberes construídos ao longo da vida. Quando o novo CRAS foi inaugurado o grupo Grupo Compartilhando Saberes começou a receber outras mulheres, que por sua vez eram beneficiárias dos programas sociais PAIF e SCFV. 


\section{CONTEXTO E DETALHAMENTO DAS ATIVIDADES}

Estudo descritivo (GIL, 2002; 2008), do tipo relato de experiência - RE onde "O RE está compreendido como um trabalho de linguagem, uma construção que não objetiva propor a última palavra, mas que tem caráter de síntese provisória, aberta à análise e à permanente produção de saberes novos e transversais." (DALTRO; FARIA, 2019, p. 235) construído no contexto do estágio interdisciplinar obrigatório do curso em Licenciatura em Educação do Campo - Ciências da Natureza pela Universidade Federal do Rio Grande do Sul. Tendo como objetivo apresentar a aplicação de uma abordagem temática (FREIRE, 1997; 2009; 2013; 2014) em Ciências da Natureza em um espaço não formal.

A prática foi aplicada em em quatro etapas: a etapa de investigação - onde se consistiu na observação e aprofundamento da temática pesquisada, entrevista coletiva e a construção do tema gerador (título da abordagem temática); etapa de tematização - visita em uma horta biodinâmica localizada em um Assentamento da Reforma Agrária do município com objetivo de contextualizar o tema; a etapa de problematização - Roda de Conversa para aproximar e compartilhar informações, assuntos, dúvidas, impressões mobilizados na visita a horta (momento da tematização); etapa 04 organização e sistematização do conhecimento - Oficina de sabão coletiva com atravessamentos evidenciados nas etapa anteriores.

\section{ANÁLISE E DISCUSSÃO DO RELATO}

A partir do misturar, manusear, experimentar, observar e do criar foi possível por meio do tema introduzir, organizar e construir diálogos em comum entre os conteúdos curriculares e a experiência das participantes, contribuindo com a afirmação de outras possibilidades de compreender e construir a autonomia individual e coletiva (FREIRE, 1997) através de conteúdos curriculares e saberes cotidianos.

Em diversos momentos a atividade que parecia monótona, se transformava em uma proposta coletiva e participativa sendo possível inserir diversas áreas do conhecimento e saberes que não são produzidos com certa frequência em espaços escolares formais mas são oriundos das suas próprias existências, experiências, necessidades e de seus lugares de origem.

A inserção e a participação das participantes, mesmo que muitas vezes tímida nos processos de integração coletivos, foi possível criar oportunidades de vivenciar e produzir experiências e reflexões, dando impulsos para a investigação de novos/outros saberes e práticas em Ciências da Natureza em espaços não formais, demonstrando uma complementaridade positiva entre o espaço formal e o não formal (AFONSO, 2001) através dos princípios dialógicos e problematizadores a qual propõe Paulo Freire ( 1997; 2013) onde os sujeitos são co responsáveis pelos processos e conhecimentos adquiridos e construídos. 
O questionário aplicado inicialmente como parte da etapa de investigação da temática resultou em informações econômicas, culturais e sociais importantes, sendo possível observar a diversidade de histórias e narrativas de vida das participantes, também foi possível perceber características importantes de proximidade entre as questões ligadas à temática e práticas cotidianas das mesmas como por exemplo onde as misturas estavam presentes em seu dia a dia, em suas relações com outras pessoas, a conteúdos acessados na internet ou por outras mídias de comunicação como rádio e televisão, consolidando saberes escolares com saberes organizados e produzidos a partir da experiência de vida de cada participante (DELIZOICOV, 2008).

$\mathrm{Na}$ segunda etapa nomeada como tematização as participantes foram organizadas em um passeio para conhecer uma horta orgânica em um Assentamento da Reforma Agrária no mesmo município. A agricultura que recepcionou o grupo apresentou a horta e as dinâmicas que envolviam o trabalho e cultivo da terra, apresentou os canteiros de cultivo, o açude, a padaria da família e o quintal da sua casa.

Em uma roda de conversa no meio de verduras, legumes e a sombra de pés de bananeiras a agricultora emocionou a todas participantes com a sua trajetória e história de luta junta ao Movimento dos Trabalhadores Sem Terra - MST mobilizando memórias e histórias das participantes em relação a terra, preservação e conservação da natureza, hábitos de consumo, alimentação saudável, contribuindo na aproximação de saberes provenientes do cotidiano delas com saberes escolares.

A etapa de problematização consistiu em diálogos coletivos sobre o passeio e as impressões das participantes em conhecer o espaço da horta. Esta etapa permitiu criar trânsitos e redes de aproximação em relação a Ciências da Natureza num contexto da Educação do Campo (no caso a horta que foi visitada) com experiências presentes no cotidiano das participantes. Neste momento inúmeros assuntos foram levantados como alimentação saudável, agrotóxicos, acesso a comida de qualidade, acesso pela terra e moradia digna, acesso à educação, saúde e trabalho. Está etapa permitiu o Faprofundamento em relação à diversidade de saberes que são contextualizados, organizados e aplicados, demonstrando diferentes redes e atravessamentos que constituem e se apresentam no cotidiano das mulheres participantes.

Para finalizar a atividade a etapa 4 consistiu em um momento de organização e sistematização dos saberes que foram mobilizados pelas participantes ao longo das etapas anteriores, este momento também favoreceu o diálogo sobre assuntos como o autocuidado através de produtos naturais que podem ser produzidos de forma autônoma sem precisar utilizar produtos químicos que agridem o bem estar, ambiente e saúde do corpo.

Ao fazer a receita de sabão as participantes praticaram e aplicaram assuntos e saberes ligados à produção do sabão como misturas naturais e químicas, calor e a interação do ser humano no ambiente, além de fazer um resgate de todos os conhecimentos mobilizados ao decorrer das etapas anteriores. 
Através da abordagem temática foi possível verificar novas possibilidades de ensino aprendizagem relacionando assuntos e conhecimentos escolares de Ciências da Natureza com saberes presentes no espaço não escolar das participantes. Demonstrando um campo fertil para metodologias didáticas centradas nos educandos, estimulando novas perspectivas no ensino e aprendizagem em Ciências da Natureza, sobretudo integrando os espaços formais e não formais.

\section{CONSIDERAÇÕES FINAIS}

Tendo a consciência que o conhecimento não parte apenas da escola e a compreensão que a escola ainda é um lugar privilegiado para o acesso do conhecimento, podemos nos desafiar a partir da problemática que é o currículo atual em construir formas coletivas para novos caminhos, onde os espaços educativos tenham transformações diárias, que permitam a superação de contradições presentes em nossa sociedade, e que se possa ter novos horizontes dos caminhos já construídos, onde outras propostas de aprendizagem e alternativas pedagógicas visem promover a produção de conhecimento e transformações profundas nas condições e relações de vida dos diversos sujeitos inseridos nos processos educativos.

Nesse sentido o tema desenvolvido teve como principal objetivo e validade orientar, gerar, questionar e aglutinar dentro de um grande guarda-chuva, os assuntos curriculares previstos e saberes produzidos cotidianamente pelas participantes.

Sendo assim, a experiência desenvolvida oportunizou a presente reflexão, autocrítica e futuros desafios, tal como pensar como os espaços não formais, como a própria escola pode contribuir como ferramenta de construção de novos paradigmas onde o educando seja o principal motivador-construtor de seus conhecimentos acerca da

Reviências da Natureza.

\section{REFERÊNCIAS}

AFONSO, Almerindo Janela. Os lugares da educação. In: VON SIMSON, Olga Rodrigues Moraes de.; PARK, Margareth Brandini; FERNANDES, Renata Sieiro. (Org.). Educação não-formal: cenários da criação. Campinas: UNICAMP/Centro de Memória, 2001. p. 29-38.

DALTRO, Mônica Ramos; DE FARIA, Anna Amélia. Relato de experiência: Uma narrativa científica na pós-modernidade. Estudos e Pesquisas em Psicologia, v. 19, n. 1, p. 223-237, 2019.

DELIZOICOV, Demétrio. La educación en ciencias y la perspectiva de Paulo Freire. Alexandria: revista de educação em ciência e tecnologia, v. 1, n. 2, p. 37-62, 2008.

Recebido em: 30 /04/ 2020 
FREIRE, Paulo. Pedagogia da Autonomia. Saberes necessários à prática educativa 2 ed., Rio de Janeiro: Paz e Terra, 1997.

Pedagogia do oprimido. 48. reimp. São Paulo: Paz e Terra, 2009.

Extensão ou comunicação?. Editora Paz e Terra, 2013.

Pedagogia da esperança: um reencontro com a pedagogia do oprimido.

Editora Paz e Terra, 2014.

Gil, Antônio Carlos, 1946- Como elaborar projetos de pesquisa/Antônio Carlos Gil. 4. ed. - São Paulo : Atlas, 2002.

Métodos e técnicas de pesquisa social / Antonio Carlos Gil. - 6. ed. - São Paulo : Atlas, 2008.

JACOBUCCI, D. F. C Contribuições dos espaços não formais de educação para a formação da cultura científica. Em extensão, Uberlândia, v.7, 2008.

ROCHA, Sônia Cláudia Barroso da; FACHÍN-TERÁN, Augusto. O uso de espaços não formais como estratégia para o ensino de ciências. Manaus: UEA/Escola Normal Superior/PPGEECA, 2010.
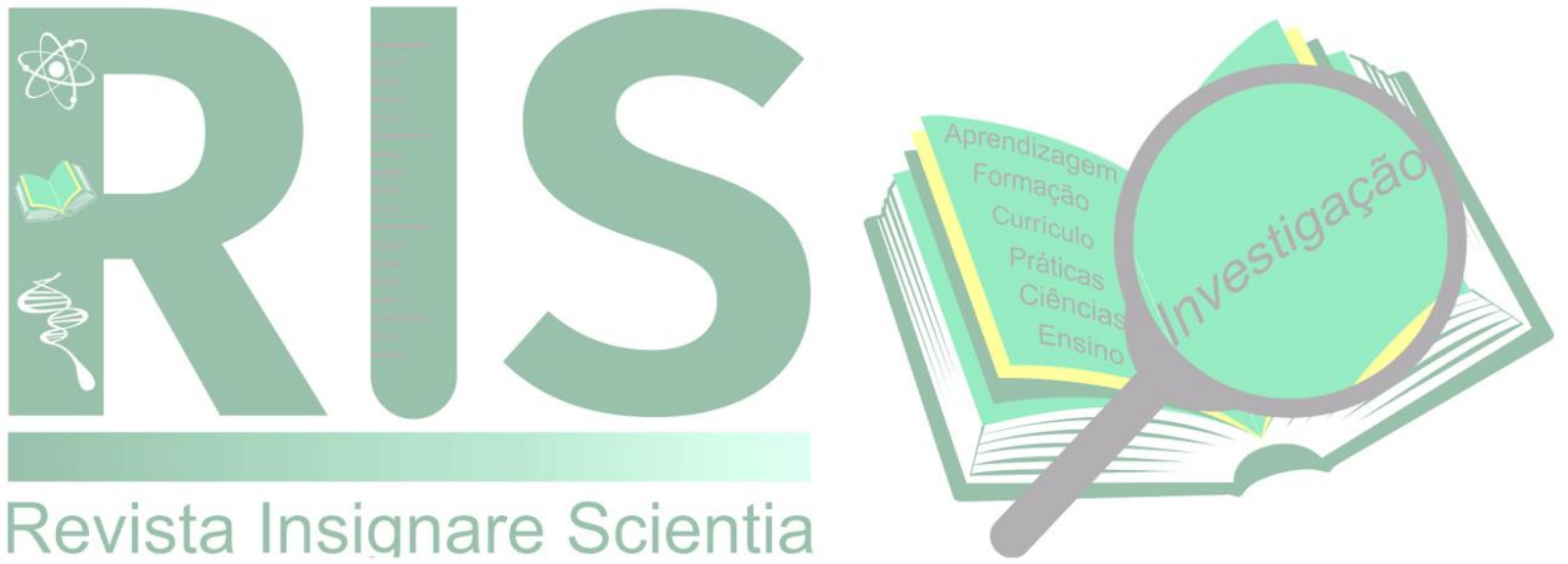